\title{
ENTERPRISES RETAIN HIGH PROPENSITY FOR ADAPTABILITY ${ }^{1}$
}

\author{
S.Tsukhlo
}

Assessment of the state of affairs in Russian industry and the level of its adaptability to real conditions as of Q1 2016 demonstrated rather positive values of the normal index that reflects the estimation by the enterprises of indicators and conditions of their activity. Industry retains a high level of adaptability to all shocks of recent seven quarters.

The final evaluation of the normal index (adaptability) for the last quarter (Fig. 1) has been upgraded according to the results of March survey owing to the positive correction of the stocks of finished products and satisfaction with demand compared to the previous assessment obtained by the period-end for January-February 2016. However compared to Q4 2016, a decrease in the estimates of demand and capacities were registered. Meantime, satisfaction with demand demonstrated maximum decline against intercrisis maximum (60\%) of this indicator posted in 2011. Estimates of capacity sufficiency deteriorated against that maximum but owing to the growth of responses "more than sufficient," which can not be considered as an undoubtedly negative factor. Other components of the aggregate indicator lost against their maximum and appraisals of stocks of finished products reached the maximum level in Q1 2016.

Branches of Russian industry demonstrate different level of entering the new normal of 2016 (Fig. 2).

\section{Achievements of the food industry}

Index of Adaptability of the food industry has reach an absolute (for 19942016) maximum of $84 \%$. In other words, $84 \%$ of businesses considered normal the volumes of demand, stocks, capacities, number of workers and their finan-

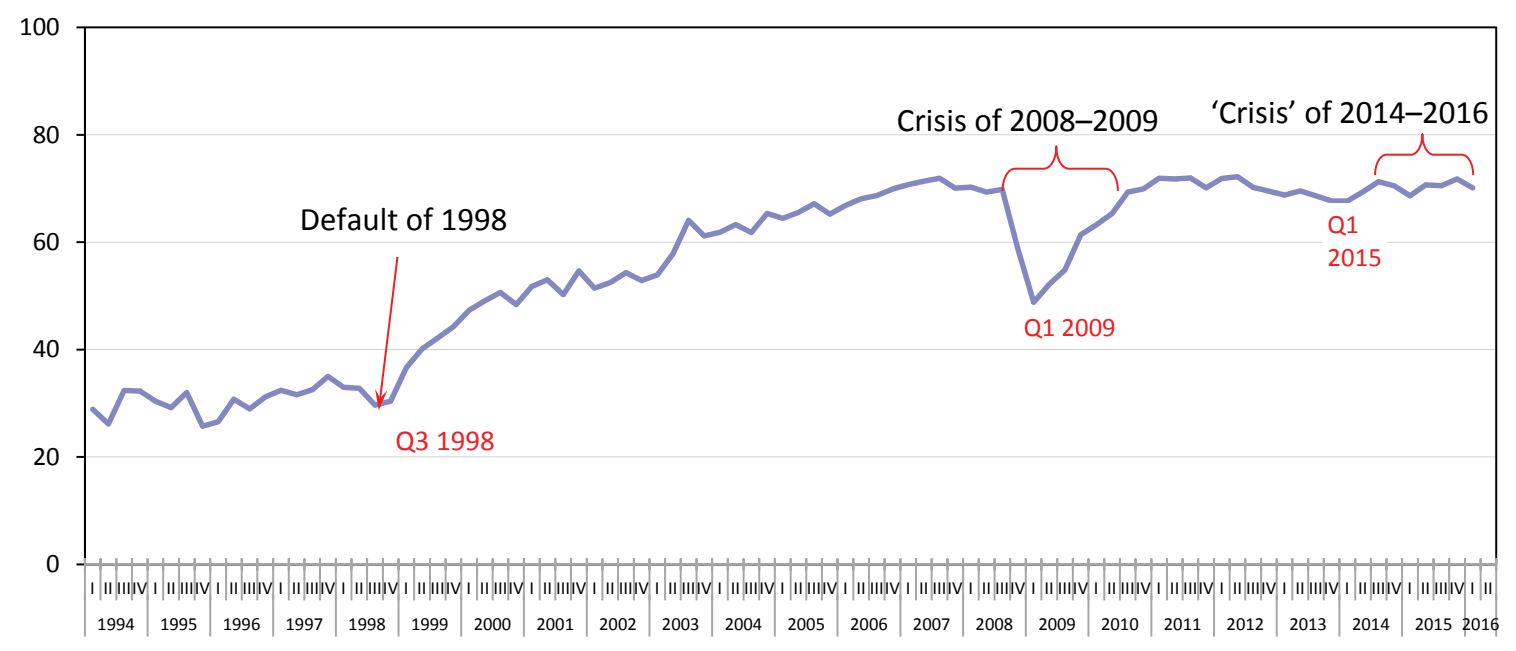

Fig. 1. Adaptability Index (normal) of industry, 1994-2016, \% (share of enterprises assessing their indices as 'normal')

1 This paper was originally published in Online Monitoring of Russia's Economic Outlook No.7(25). 


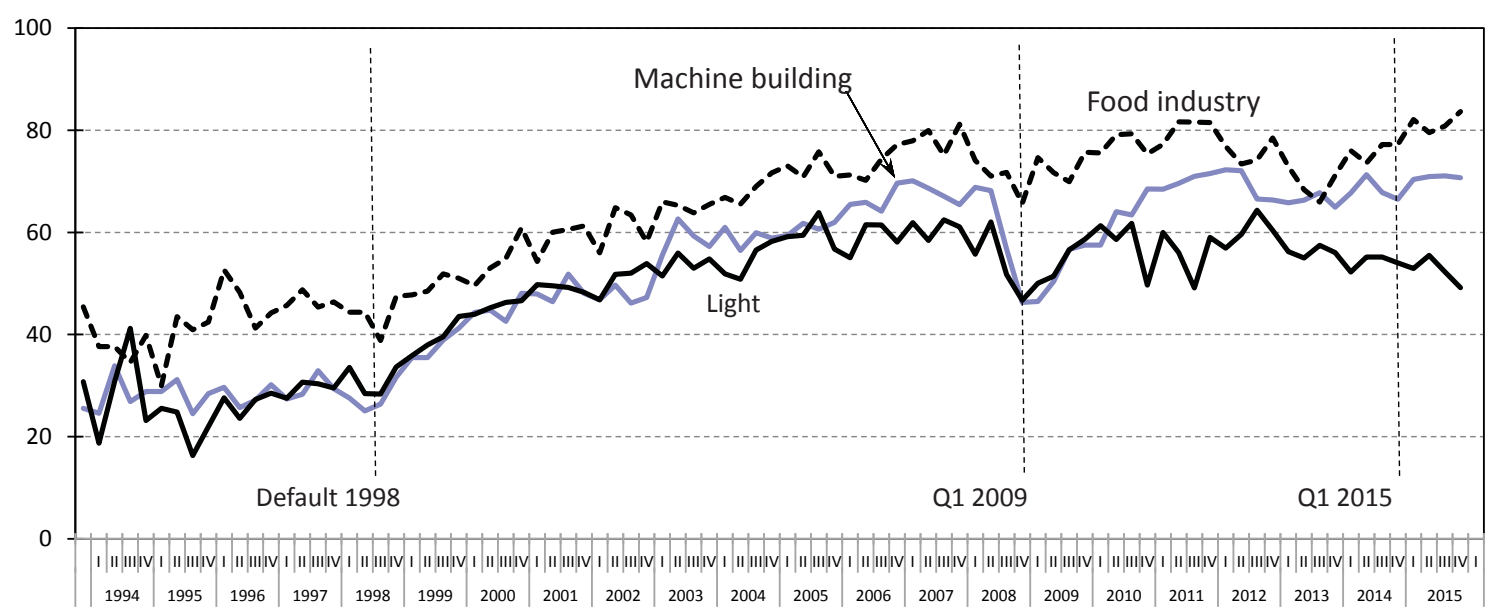

Fig.2. Industrial Indices of adaptability (normal), 1994-2016, $\%$ (share of enterprises that assess their indicators as "normal")

cial and economic situation in Q1 2016. Although in Q4 2013, this sectoral indicator declined to the crisis (2008-2009) minimum of 66\%. However, this industry has not been demonstrating confidence over recent quarters. Satisfaction with demand (for the normal evaluations of its volume) shed 14 p.p. during two quarters and declined to $53 \%$ now. The food industry hoped, most likely, for large marketing volumes of domestic products amid counter-sanctions and ruble's devaluation. However, the Russians have "tightened their belts" and started not only to earn less in real terms but also to spend less on food. At the same time, the industry as never before is sufficient with resources required for domestic production. Nearly all food-processing enterprises (96\%) have normal sufficiency with inputs, $91 \%$ - with headcount, $87 \%$ - with capacities, and $85 \%$ - with stocks of finished products. As a result, $90 \%$ of businesses assess their financial and economic situation as good or satisfactory.

\section{Problems of the light industry}

The light industry is at the other pole now. Barely $49 \%$ of enterprises managed to adapt to the conditions of the protracted crisis of 2014-2016 by Q1-end 2016, which is the worst indicator since Q1 2009 (i.e. since the last crisis). Then, the industrial index of adaptability fell to $47 \%$. However, the indicator was still worse by the end of crisis-year $1998-28 \%$. The best value of the indicator was posted in 2005 and 2012.

Deterioration of the light industry industrial index values is, first of all, due to insufficient demand. At the turn of 2016, barely $13 \%$ of enterprises of the industry were satisfied with demand volume, although in mid-2015 this indicator was 3-fold higher, and during the inter-crisis peak (2010) was 4 times higher. Inferior values of demand satisfaction were registered only in 1998 and 1996. The industry was not boosted by the ruble's devaluation as was expected. Obviously, it was doe to consumers' behavior.

Other assessments made by the light industry enterprises have not undergone such critical changes, although they are far from the values registered in better time. Only $51 \%$ of enterprises estimate their stocks of raw and other materials as normal - they do not manage to purchase everything at acceptable prices in the context of falling demand. At the same time, the share of 
responses of excessive stocks of inputs went up, which is already explained by mistakes made during purchases of raw materials. Stocks of finished products are considered as normal by $57 \%$ of enterprises amid significant prevalence of responses "above normal" over responses "below normal", which one more confirmation of the marketing issues. Fifty five percent of enterprises register capacity sufficiency with 36 percent of enterprises posting their excess. Since mid-2014, evaluation of capacities experience considerable fluctuations (the share of normal responses changed during this period from 42 to $72 \%$ ). This signifies that the enterprises are unsure in their assessment of the near future of the industry. Best of all, the light industry is sufficient with headcount - 62\% of normal responses in Q1 2016.

\section{Confidence of the machine building industry}

Index of Adaptability in machine building demonstrates stability following the decline of Q1 2015 when the industry was in to panic and degraded estimates related to the situation awaiting a full-scale crisis of 2008-2009. However, the reality turned out to be quite different and from Q2 2015, the machine building industry gave positive assessments and up till now retains $70 \%$ level of adaptability to the new normal.

Although, the machine building enterprises practically always assess the demand volume less well than other indicators during many years of our monitoring. However, its current evaluation (Q1 2016) did not undergo critically crisis shifts compared the previous years.

Appraisals of stocks of finished products, which in 2015-2016 reached alltime high of normality, demonstrate that the industry successfully copes with the main shocks of recent years and in its absolute majority is ready for the awaited surprises of the current crisis. The share of enterprises with insufficient stocks of finished products at the turn of 2016 remains at the all-time low. Lower value of the indicator was obtained solely in 1992 and it is incorrect to compare 2016 with 1992.

Stocks of raw and other materials are at the all-time maximum of normality and confirm resolve of the industry to upcoming triumph over crisis.

The industry is well sufficient now with industrial capacities and headcount. This is due to "expected shifts in demand." To that end, $20 \%$ of enterprises even have excess capacities. However, $10 \%$ of machine building plants all the same consider their industrial capacities insufficient for the satisfaction of expected shifts in demand for their products. However, the sectoral balance remains positive, i.e. the industry boats of excessive industrial capacities. Russian machine building registers such situation for the eighth year in a row - since 2009.

Russian machine building industry is worse provided with personnel. Although, the share of "normal" responses of the available headcount (again "due to expected shifts in demand") is higher (i.e. better than capacities estimates) and solely is one point behind the all-time maximum of the 21-year monitoring. However, among other part of the machine building plants responses "below normal" dominate over the responses "more than sufficient." In other words, in 2016, the industry incurs a deficit of headcount. Excess of personnel was registered in machine building solely in 2009 and 2010. During all other years the industry was operating amidst the deficit of personnel including 2015.

Positive state of the industry allowed $87 \%$ of enterprises to estimate their financial and economic situation as normal. This result posted at the turn of 2016 was a repetition of the situation of 2007. 